\title{
26 \\ Customer Value Profiling: Continuously Benchmarking What Matters Most - Value Delivered to the Marketplace
}

\author{
Barbara Napier and Steve Crom
}

\section{INTRODUCTION}

In today's rapidly evolving markets, it is no longer sufficient for organizations to rely upon traditional benchmarking data gathered in the traditional manner. In order to provide value to the marketplace and keep a competitive edge, more and more organizations are learning to use feedback from customers as an essential new source of benchmarking data. We propose the use of the Customer Value Profile as a new method of benchmarking market forces from the customer's perspective. This new method relies on two key philosophical premises: 1) benchmarking market realities and preferences from the customer's perspective is better than benchmarking the performance of competitors or other industry leaders, and 2) a process of customer value analysis and process improvement that is led by the internal employees is superior to one which is led from an external source. Each of these premises are explored in depth in the following section, followed by a description of a new method of benchmarking customer value, the Customer Value Profile.

\section{THE ADVANTAGES OF A CUSTOMER PERSPECTIVE IN BENCHMARKING}

Most companies have realized by now that quality is just the price of admission in the competitive race to become a market leader. As we look past Total Quality to the future, we see that providing better value from the customer's perspective is the next step in the evolution toward improved organizational performance. Customer's perceptions of how well an organization is doing as a supplier (of goods or services) is the ultimate performance benchmark -- benchmarking the competition is no longer sufficient. By setting performance targets based on what the competition is doing, an organization risks always being second best. It is only by keeping your eye on the ultimate judge of performance, the customer, that the ultimate performance gains can be had.

There are several advantages of benchmarking customer's perceptions of performance. First, listening to issues raised by customers allows you to determine what they think is important, and what issues are most likely to affect their buying behavior. This information can then be used to calibrate internal benchmarking data to provide ongoing performance feedback to your employees, and to prioritize breakthrough improvement efforts to respond to the customer's needs. This ensures that you are working on improving the most important things, rather than nice-to-have peripheral issues that don't really affect buying behavior or ultimately market share. Second, customers can tell you what needs they have that are not currently being met. From that information you can take this information, possibly in partnership with your customers, and create innovative new services or products they would 
like to have, that maybe neither you nor your competition currently supply. The company closest to the customer who actively listens best gets the jump on the competition in developing innovations first, rather than hearing about them after someone else brings them to market. Third, customers can give you their perspectives on your relative market placement, so that you know what your strengths and weaknesses are from their perspective. Fourth, the act of listening to your customers will necessarily draw you closer together, and help to cement the relationship and increase customer loyalty. The method of having employees involved in the benchmarking process further cements this relationship; the advantages of employee involvement are outlined below.

\section{EMPLOYEE INVOLVEMENT IN CUSTOMER BENCHMARKING}

The general phenomenon of listening to the views and opinions of customers is well known, although usually conducted through third party market research. The method used for benchmarking with Customer Value Profiling, however, is different in several important ways. First, Customer Value Profiling is conducted primarily by internal employees of your organization, who identify themselves as such in their interviews with customers. The objectivity of pure data collection which is forfeited by introducing bias (which is not found when "blind" market research is conducted) is outweighed by the many advantages (outlined below) of this new method of data collection. Second, Customer Value Profiling starts with a qualitative component conducted by employees, which explores in the customers own words what their most important issues are. Only after this qualitative experience has been digested and understood by the employees is a quantitative component conducted. Therefore, the benchmarking data has both a quantitative and a qualitative segment, with both enriched by the employees having taken a leadership role in data collection. Third, the Customer Value Profiling process is by definition customer centered; rather than finding out about the marketplace, or about the competition, you are finding out about the customers and their needs, so that you can better align your services to meet and exceed those needs. Fourth, rather than assessing satisfaction with services currently rendered, a key focus of a Customer Value Profile is to uncover innovative new approaches that delight the customers, rather than just satisfy them.

Having employees from a cross section of your organization participate first hand in listening to the customer has a wide variety of benefits over having just one functional department responsible for benchmarking data gathering, or out-sourcing the data gathering to a third party. These benefits far outweigh any bias in pure data collection which is introduced by not having an objective third party interfacing with your customers. First, as employees learn more about the needs of the customers, they also experience first hand the importance of listening to the customer's voice. This helps to ensure that the customers are involved in the decision making and process improvements efforts after the data collection process is finished, since the customer has dozens of new advocates throughout your company. Second, since employees are personally going to customers to find out what is important to them, both the employees and the customers get a strong message that your organization is taking this process very seriously, and that clear and directed changes will result. Third, there is less internal resistance to change since these changes are understood by 
the employees, and are in fact led by them as well as they participate in task--team process improvement efforts.

Fourth, as mentioned earlier, simply by taking part in the dialogues, the employees play an important role in improving relations with your customers. Fifth, since employees take part first hand in conversations with customers, the resulting benchmarking data comes alive for everyone in a way that isn't possible when they are just handed a data summary. Mean scores and standard deviations are cold and meaningless compared to memories of dialogues and meaningful anecdotes. Sixth, most improvement efforts will involve some level of cross functional cooperation within your organization in order to achieve breakthrough improvement. Having a cross section of employees from as diverse department as sales, operations, marketing, research, and administration involved in the data gathering process begins to model the cross functional cooperation that will make those breakthrough improvements possible.

\section{CUSTOMER VALUE PROFILING METHOD}

The following sections describe the new method of Customer Value Profiling, as developed by the consulting firm of Rath \& Strong Management Consultants, from Lexington, Massachusetts. This benchmarking method has been used by several organizations in the United States and Europe to create a system for benchmarking real-time the performance of essential processes, prioritize breakthrough improvement efforts, and incorporate the voice of the customer in their decision making processes. During this partnership, skills necessary to conduct this benchmarking on an ongoing basis are transferred by Rath \& Strong consultants to the clients. This process involves interview skills, quantitative and qualitative data analysis abilities, questionnaire development skills, the creation of benchmark indices, and task-team process improvement abilities. Each of these are learned throughout the Customer Value Profile process.

A Customer Value Profile is a summary of an organization's market placement, measured on dimensions that are described as most important by their customers. Each dimension has, by definition, a "Market Average Value (MAV)." The MAV is, essentially, the industry norm for the quality of goods or services offered to a marketplace, or the marketplace "par." As mentioned earlier, providing excellent quality has become "par" in most venues. In order to succeed today, an organization must strive to be above par, or above the MAV point.

Since the goal is to improve processes, the first step is to identify the most important dimensions to the customers: the Value Descriptors. These Value Descriptors are later operationalized by employees into Value Indices. These Value Indices, when placed on a histogram with an assessment of the MAV, are collectively referred to as a Customer Value Profile. This Customer Value Profile is then used to target breakthrough improvement efforts, determine business strategy alterations, or uncover possible organizational restructuring, training or hiring needs, depending on the outcome. A summary of the Customer Value Profile Process is presented below, followed by some concluding comments. 


\subsection{Orientation}

During the orientation phase, Rath \& Strong consultants learn as much as possible about the issues facing our client organization (hereafter referred to as "our organization"): internal strengths and weaknesses, market forces, history, etc. At the same time, we introduce the theory of Customer Value Profiling to employees at various levels of our organization, in a variety of organizational functions. At this point, employees who will be involved in the first stage of interviews are chosen and their role in the process explained.

\subsection{Initial Market Contact}

Initial market contact is conducted in order to determine, in the customers' own words, what issues are most important to them in choosing a supplier (of goods or services, hereafter referred to simply as supplier). Employees take part in these interviews primarily in an observer role; employees from management, sales, marketing, production, or a variety of other roles may be chosen to take part of these interviews. Interviews are arranged in order to have a sample of participants who as accurately as possible represent the actual range of different types of customers, stratified by size, geographic location, market sector, or any other relevant characteristics. Furthermore, non-customers (potential customers or former customers) are included as well (hereafter, the term "customers" refers to potential as well as actual customers). Typically, 15 - 20 interviews are sufficient, depending on the complexity of the market.

During these initial interviews, open ended questions are asked in order to get a better understanding of what things are most important to customers when they are evaluating current suppliers, or making a decision to choose a new supplier. Questions are also asked to determine if there are current needs that are not being met by current suppliers. A question is included to determine who is the best out of all their suppliers and why. This benchmark question often reveals superior services offered by suppliers in other fields that could possibly be transferred to this market. Other questions are also included as time permits, including questions about general market forces, specific issues facing the marketplace, projection of future changes, etc.

Finally, customers are asked to rate, on a 1 to 5 scale, our organization as well as a competitor on the issues they themselves have identified throughout the interview as being most important to them. This empirical data is used in conjunction with the qualitative data for determining Value Descriptors and getting an early picture of where our organizations' strengths and weaknesses lie.

\subsection{Develop and Review Value Descriptors}

Value Descriptors are a summary of issues raised by the customers. A thematic analysis of the issues identified throughout the interviews usually yield between 6 and 8 themes; the title given to each of these themes are referred to as a Value Descriptor. Whenever possible, these Value Descriptors should be in the customer's own words. These Value Descriptors are eventually reflected in the Customer Value Profile using internal data for real-time benchmarking of critical processes. 
Other analysis of the data collected in the initial interviews includes a summary of relative strengths and weaknesses relative to the competition, mean scores of our organization and the competition given by each customer, and a summary of any salient new information which has emerged by this point (such as information about market trends, new innovations, etc.).

This initial analysis is reviewed with the team of employees who have taken part in the interviews. The thematic grouping of issues is adjusted as necessary to reflect the employees' input. At this point, employees are asked to predict what they think the Customer Value Profile will look like, including strengths and weaknesses as reflected by placement relative to the MAV line.

\subsection{Form the Value Profile Team}

Once the preliminary data has been collected, the next step is to charter the Value Profile Team. It is important that this team be made up of top management representatives from Sales/Marketing, Operations, Finance, and Human Resources, since any changes that take place as a results of the process will probably involve each of those departments. The formation of this team helps to ensure that there is cross functional support for the entire Customer Value project. The major mission of this team is to guide policy decisions, select team members for future projects, and shepherd the change process.

\subsection{Collect Data to Create Preliminary Profile}

One of the strengths of the Customer Value Profile method is that it starts with a qualitative segment to determine the relevant issues in that particular market, and then moves on to a more quantitative segment based on that information. The quantitative data gathering procedure involves the use of structured questionnaires administered to a cross section of customers. Interviewers and observers are selected by the Value Profile Team to take part in the data gathering. Participants should have good interpersonal skills, and should come from a broad a cross section of functions and levels of the organization.

A questionnaire is developed with the help of the interview teams that reflects the issues raised in the initial interviews. The Value Descriptors are operationalized into close-ended questions, and various open ended questions are included to reflect buying behavior, demographics, needs currently being unmet, etc.

The interview teams also determine the contacts for interviews that will be made at various customers. Interviews should be stratified as much as possible to reflect the demographic make-up of our organization's customer base as well as strategically picked potential customers. For instance, interviews should span various organizational functions and levels at the customer's organization, various sizes of organizations, etc. Given the types of analyses being conducted with this empirical data and the importance it will play in determining the business strategy, it is important to conduct as many interviews as possible. Although small organizations with small customer bases are not excluded from this type of benchmarking, there should optimally be over 100 responses in this second round of interviews. 
Skills training on the do's and don'ts of interviewing is an essential step of the process. Interviewers are trained on the use of probing questions, the importance of body language, and various other aspects of interview techniques. They are then asked to role play the interviewing experience in teams of two. This role playing serves two functions: it pretests the questionnaire, and it provides data about the interviewers' perceptions of the customers' perspectives. The later can be used in subsequent data analysis to determine how accurate the employees were in their preconceived notions about the customers. If possible, the questionnaire should also be pretested on one or two customers and then adjusted as necessary.

\subsection{Analyze Results}

Results are analyzed in a variety of ways, depending on the data included in the questionnaire. As a minimum, the questions included to reflect the Value Descriptors should be analyzed to see how well they cluster together. Relationships between the Value Descriptors and various buying behavior questions should also be explored to determine relative importance of the Value Descriptors. Thematic analysis of open-ended questions should be conducted, if at all possible in conjunction with the interview teams.

Questionnaires are designed so that interviewees primarily rate the performance of their primary supplier. Since the primary supplier is identified, analysis can then be conducted on the relative strengths and weaknesses of various suppliers, including our organization. This provides important benchmarking data which is then used to form a preliminary Value Profile.

\subsection{Review Results with Team and Others}

Results of the empirical data analysis are reviewed with the Profile Team as well as the interview teams. The teams envision their ideal Customer Value Profile, and compare this ideal to the preliminary Value Profile. Teams members are asked to select employees who are closest to the processes that are indicated in the preliminary Customer Value Profile who would be most appropriate to help identify which internal metrics are available to measure those processes.

\subsection{Identify Required Metrics for Value Indices}

At this point, The Value Descriptors begin to be turned into Value Indices. Whereas Value Descriptors are important issues from the customer's perspective, Value Indices are operationalizations of those issues from the perspective of our organization. In other words, if one of the Value Descriptors was "Delivers on Demand," the Value Index might include various internal measures of delivery capability, such as number of rejected deliveries, ontime delivery rates, time elapsed between request and delivery, etc. Information which goes into making up the Value Indices should be readily available, meaningful to employees, and simple. These internal measures are combined into a Value Index.

Once internal metrics have been determined for Value Indices, metrics that must be determined by surveying customers are identified. Depending on the Value Index, short item questionnaires or other feedback procedures may be most appropriate. 


\subsection{Create Value Indices and Value Profile}

Once the metrics for the Value Indices have been determined, the necessary data is gathered together and systems for updating this information are established. Value Indices, when displayed together with estimations of MAV, form the Customer Value Profile. (MAV estimates are based on data gathered from the questionnaire). The Customer Value Indices and Customer Value Profile should be posted in a visible place and updated periodically -weekly, monthly or quarterly, as appropriate.

One of the unique features of Customer Value Profiling is the continuous nature of the benchmarking process. This method gives people at the process level information that they can use to take corrective action or make improvements to processes which have been shown to be essential to their organization's success from the customers' perspective. The real-time nature of this process differentiates it from other types of benchmarking, as an organization's performance is continuously being monitored throughout their improvement efforts and beyond.

\subsection{Prioritize Processes for Improvement}

At this point, the Profile Team has the information they need to prioritize process improvement efforts. From the data analysis, this team has information about which issues most influence buying behavior as well as about our organization's performance relative to our competition. Based on this information and other strategic concerns, the Profile Team prioritizes processes most in need of improvement. Usually two or three Value Descriptors are chosen by the Profile Team for breakthrough process improvement efforts. At this point, recommendations about possible strategic human resource improvements (hiring or training needs, restructuring) are also made.

\subsection{Develop Teams for Breakthrough Improvement Efforts}

Depending on the issues raised and priorities chosen for process improvement efforts, teams are selected and chartered to take part in those improvement efforts. We recommend focusing on how the team will work together before launching into problem solving efforts. Teams that do not succeed in process improvement efforts usually have great ideas, but cannot get along, or work together to agree on a improvement strategy that everyone will support.

\subsection{Communicate the Profile and Key Processes to be Improved}

Once the strategic decision of which key processes will be improved has been made, the newly created Customer Value Profile should be communicated to all staff members, along with priorities and rationales for process improvements. The improvement teams should be announced along with their charters for improvement efforts. It is really important at this point to reinforce that every employee has an impact on the services provided to the custorner, and ask that everyone take some time to identify ways in which their activities impact one or more of the value descriptors. The Customer Value Profile philosophy and process should be explained to everyone, including systems in place to communicate progress in improvement efforts through regular postings of Value Indices. Each employee should be asked for suggestions on how to reach improvement goals. 


\subsection{Monitor Value Indices Over Time and Adjust When Necessary}

The Value Indices are updated and posted on a regular ongoing basis. In addition, the Customer Value Profile process will need to be repeated on average about once every two years, depending on the changes in the marketplace.

\section{CONCLUSIONS}

The ultimate goal of any business is delivering value to the marketplace, thereby increasing market share. By going directly to the customers and determining what value means to them, organizations can improve their abilities to meet and exceed the customers expectations. By focusing your benchmarking efforts on the perceptions of the customers, then internalizing these perceptions into commonly recognized metrics, your entire organization will move closer to the customer. When anticipating their needs then excelling at meeting those needs becomes second nature, increased market share will undoubtedly follow.

Author's Note: The Authors gratefully acknowledge the contributions made by John Guaspari in the co-development of Customer Value Profiling. 